uncertainty about how the question of funding would develop over the next two or three years.

Collins says that gauging future costs is difficult as it is not clear how quickly the US sequencing laboratories will gain capacity. Nor can it be predicted how quickly or how far sequencing costs will fall. But "no one should make the mistake of assuming that we have locked in this $\$ 60$ million a year and that's all there's going to be. If we have to find more, we will."

With fewer than 3 per cent of the genome's 3 billion bases sequenced so far, institute officials are also facing the complex challenges of recruiting scientists and of increasing at least tenfold the country's sequencing capacity in order to complete the job in time.

Eric Lander, director of the Whitehead Institute at the Massachusetts Institute of Technology, told last month's meeting: "I'm concerned that, the way the major sequencing is going, we're not going to be attracting any new young blood."

Those present at the meeting debated strategies for establishing sequencing centres and expanding existing ones while improving quality and efficiency. Another problem discussed was how to cost accurately the sequencing of a base pair to allow budget planning and comparisons of competing grant applications.

\title{
Indian guidelines allow limited gene screening
}

[NEW DELHI] The Indian Council of Medical Research has released draft ethical guidelines on biomedical research. These would allow genetic screening in employment with the consent of employees, but prohibit life insurance companies from making tests a prerequisite for insurance.

The guidelines would also allow medically terminated fetuses to be used for transplanting to "patients for whom no other form of treatment is available". But a strict ban on animal-to-human transplants is proposed.

The panel, headed by M. N. Venkatachalaiah, a former chief justice of the supreme court, has updated guidelines issued in 1980. It has included regulations for research into areas such as human genetics, organ transplantation and assisted reproduction.

Employee screening is justified for genetic disorders that might jeopardize the safety of others. Thus airline companies can screen pilots for sickle-cell anaemia, which can affect an individual's actions when "exposed to atypical atmospheric conditions", endangering the lives of passengers.

But family members should not be entitled to know one another's genetic diagnosis because in India "revealing the information that the wife is a carrier of a recessive disease may lead to the husband asking for a divorce". But if a person has ADS, it should not be kept secret, the report says.

Genetic screening is at present voluntary in India (although screening newborn babies at risk may be made compulsory). Prenatal diagnosis is permitted only where it is relevant to the health of the fetus or mother - not to select for sex.

The guidelines allow research on human embryos up to 14 days old and also the creation of 'abnormal' embryos using sperm and eggs taken from high-risk parents to study the transmission of genetic disorders.

But the transfer of any manipulated embryo to a human uterus, and the commercial exploitation of embryo research, would be banned.

All international collaborations involving human genetic research would be subject to regulations laid down by the Indian government. No DNA samples are allowed to leave India without adherence to previously established guidelines.

K.S. Jayaraman 